Research Article

\title{
Hazard Exposure and Health Assessment of Construction Workers in New Delhi, India
}

\author{
Aakanksha Bharti', Jugal Kishore ${ }^{2}$, Mayank Bharti ${ }^{3}$, Rhea Bharti $^{4}$, Deepak Yadav \\ Prateek Goyal $^{6}$
}

${ }^{1}$ Senior Resident, ${ }^{2}$ Director Professor \& Head, ${ }^{5,6}$ Post Graduate Student, Department of Community Medicine, VMMC \& Safdarjung Hospital, New Delhi, India.

${ }^{3,4}$ Intern, Maulana Azad Medical College, Delhi, India.

DOI: https://doi.org/10.24321/2454.325X.202009

I $\quad \begin{array}{lllll}\mathbf{N} & \mathbf{F} & \mathbf{O}\end{array}$

\section{Corresponding Author:}

Aakanksha Bharti, Department of Community Medicine, VMMC \& Safdarjung Hospital, New Delhi, India.

E-mail Id:

aakanksha.bharti@gmail.com

Orcid Id:

https://orcid.org/0000-0002-8851-8925

How to cite this article:

Bharti A, Kishore J, Bharti M, Bharti R, Yadav D, Goyal P. Hazard Exposure and Health Assessment of Construction Workers in New Delhi, India. Int J Preven Curat Comm Med 2020; 6(2): 22-27.

Date of Submission: 2020-10-23

Date of Acceptance: 2020-11-21
$\begin{array}{llllllll}\mathbf{A} & \mathbf{B} & \mathbf{S} & \mathbf{T} & \mathbf{R} & \mathbf{A} & \mathbf{C} & \mathbf{T}\end{array}$

Introduction: Construction workers are at a risk of a number of healthrelated problems, and are exposed to a plethora of occupational hazards. Due to dearth of studies on construction workers about various determinants playing key role on their health.

Objectives: 1) To determine the socio-demographic status of construction workers. 2) To assess workplace hazard exposure among study subjects. 3) To evaluate the overall health of the study subjects.

Method: An opportunity was created in a general health camp organised by Department of Community Medicine, VMMC and Safdarjung Hospital, Delhi in collaboration with Central Public Work Department (C.P.W.D) Officers' Wives Association. All the construction workers attending the health camp were approached and only those who consented were included in the study. An interviewer administered questionnaire was filled for all the study subjects. Along with the questionnaire, detailed clinical examination was done, blood pressure and random blood sugar was measured. Simple tables and cross tables were made to present the data.

Result: Total 129 construction workers were included in the study. Nearly $87 \%$ of the workers were employed on temporary or contract basis. $63.6 \%(n=82)$ spent 8 to 12 hours per day at work. Around half of the construction workers earned Rs. 10,000 per month or less. Thermal stress affected the maximum number of workers (54.3\%), followed by dust (53.5\%), followed by noise (38\%). Around $10 \%$ (13) of the workers complained of having some health problem. Various complaints were generalised body ache, headache, weakness, fever, cough, cold, blood in sputum, decreased appetite and blood in stools.

Conclusion: Construction workers are suffering from adverse health problems. There is the importance of regulating work hours of construction workers, periodic training on safe work culture and ways to reduce workplace injuries.

Keywords: Occupational Injury, Occupational Hazard, Constructions workers 


\section{Introduction}

Construction industry involves a large workforce for a huge economic activity in India. Economic development refers not only to creation of job opportunities, but also ensuring the overall well-being and safety for each worker. Construction workers are at a risk of a number of health-related problems, and are exposed to a plethora of occupational hazards. Hard physical labour, in compromised conditions like adverse weather and long working hours, puts their health at stake. The effect on worker's health can in turn affect the whole family. Construction work is considered to be one of the most hazardous sectors which poses a great risk to the worker's overall health, by exposure to various types of risks such as thermal stress, cold, noise, vibration, welding, radiation, pressure, chemicals, smoke, acids etc.

Construction workers are usually employed on a temporary basis, without any insurance or provision of basic health services. In addition, lack of awareness and knowledge about correct hygiene practices, right posture, importance of personal protective equipment together affect the general condition of the workers. Almost all the body systems including respiratory system, musculoskeletal system, cardiovascular system, gastroenteric system can be affected due to different exposures.

The International Labour Organisation estimated that injuries and illnesses related to work account for 1.1 million deaths per year worldwide. ${ }^{1}$ These deaths can be attributed to work related diseases or work-related injuries. Moreover, there is difficulty in estimating the actual burden as the occupational and non-occupational diseases cannot be easily distinguished. This results in underdiagnosis of most occupational diseases.

In India, construction industry alone provides employment to about 40 million people. ${ }^{2,3}$ A number of factors play a significant role in determining a worker's health, like age, gender, place of origin, language barrier and access to healthcare. In India, majority of the workers (92\%) are involved in informal employment, and even amongst them, a large percentage do not have any social protection and have low earning. Even in the organised sector, the scenario is quite similar. Around half of the workers are self-employed and about one third are casual labourers who seek employment daily. Only about $18 \%$ of the employed workforce are regular workers, and less than $8 \%$ have regular, full time employment with social protection. ${ }^{4}$

In India, little work has been done on construction workers who are usually poor and vulnerable. Due to dearth of studies on construction workers about various determinants playing key role on their health, the current study was planned with the following objectives: 1) To determine the socio-demographic status of construction workers in
New Delhi. 2) To assess workplace hazard exposure among study subjects. 3) To evaluate the overall health of the study subjects

\section{Methodology}

An opportunity was created in a general health camp organised by Department of Community Medicine, VMMC and Safdarjung Hospital, Delhi in collaboration with C.P.W.D Officers' Wives Association.

Department of Community Medicine, VMMC has been providing comprehensive health care with preventive, promotive and curative components through various outreach activities, camps and health centres throughout Delhi. Central Public Work Department (C.P.W.D) Officers' Wives Association is a socio-welfare organization providing welfare services to construction workers.

Sample: All the construction workers attending the health camp were approached and only those who consented were included in the study. An interviewer administered questionnaire was filled for all the study subjects. The questionnaire consisted items on socio-demographic details, working hours, exposure to hazards, history of workplace injuries and alcohol and tobacco use. Along with the questionnaire, detailed clinical examination was done, blood pressure was measured three times by automated electronic device (Omron HEM) which was calibrated with worker sitting comfortably on the chair. Average of the three readings was taken as the final recording. Random blood sugar was also measured for all the participants using glucometer under safety precautions and infection prevention and control was kept in mind.

For those requiring medication due to some illness, symptomatic treatment was given and appropriate referral was done. All those who were found to have high blood pressure and increased random blood sugar were referred to the nearest hospital for confirmation of diagnosis as well as starting of treatment.

The data was entered in a master sheet on MS Excel and later transferred to SPSS licensed Software version 20.0 for analysis. Simple tables and cross tables were made to present the data. Fisher exact test was applied to test the significance between various factors.

\section{Result}

Total 129 construction workers were included in the study. All of them were males, their age ranged from 18 years to 63 years with mean age $31.4 \pm 10.34$ years. About $46.5 \%(60)$ workers originally belonged to Bihar and $31.8 \%$ (41) workers belonged to Uttar Pradesh, the rest $(21.7 \%)$ of the workers belonged to Bengal, Orissa, Madhya Pradesh, Haryana, Punjab, Jammu and Southern states. Approximately half $(46.5 \%)$ of the workers were staying in Delhi for more than 
5 years. About $65 \%$ (84) workers were married, and only $16 \%$ workers were staying in their own house.

\section{Table I.Distribution of study subjects according to Education}

\begin{tabular}{|c|c|c|}
\hline Education status & Frequency & Percentage \\
\hline Illiterate & 45 & 34.9 \\
\hline Primary & 40 & 31.0 \\
\hline Secondary & 17 & 13.2 \\
\hline Higher secondary & 16 & 12.4 \\
\hline Intermediate & 5 & 3.9 \\
\hline Graduate & 5 & 3.9 \\
\hline Post graduate & 1 & 0.8 \\
\hline Total & 129 & 100 \\
\hline
\end{tabular}

Around one-third of the construction workers (34.9\%) were illiterate and another third (31\%) had completed primary education. Near about 40\% (51) workers were involved in unskilled labour work and $58 \%$ in semi-skilled labour work. Only 3 construction workers were doing skilled job.

Only about $13 \%$ workers were employed on a regular basis. Nearly $87 \%$ of the workers were employed on temporary or contract basis.

About three-fourths (74.4\%) of the construction workers lived in a family of 5 or less. The total number of family members ranged from 1 to 17 members.

Table 2.Distribution of study subjects according to hours spent at work per day.

\begin{tabular}{|c|c|c|}
\hline Hours spent at work/ day & Frequency & Percentage \\
\hline$<8$ hours & 11 & 8.5 \\
\hline 8 hours & 27 & 20.9 \\
\hline 8 to 12 hours & 82 & 63.6 \\
\hline$>12$ hours & 9 & 7 \\
\hline Total & 129 & 100 \\
\hline
\end{tabular}

Table 2, shows that maximum number of workers $(82$, $63.6 \%$ ) spent 8 to 12 hours per day at work. Very small percentage of workers spent less than 8 hours at work (8.5\%) and more than 12 hours at work (7\%).

Table 3, shows around half (56.6\%) of the construction workers earned Rs. 10,000 per month or less. Among these, maximum workers earned Rs. 10,000 per month. The mean income of construction workers was Rs. 11,972.87 (Standard Deviation 3942.11). The income ranged from Rs. 4000 to Rs. 25,000. On calculating the per capita income for the families of construction workers, about $58.9 \%$ of the workers had a per capita income of Rs. 3000 or less. Three construction workers had a per capita income less than Rs. 965/capita/month, that is they were below the poverty line. The mean per capita income was Rs. 4174.15 with standard deviation of Rs. 3427.07 and ranged from Rs.500 to Rs. 20,000 .

Table 3. Monthly Income and Per capita income of construction workers

\begin{tabular}{|c|c|c|}
\hline Monthly income (INR) & Frequency & Percentage \\
\hline$\leq 10,000$ & 73 & 56.6 \\
\hline 10,000 to 20,000 & 50 & 38.8 \\
\hline$>20,000$ & 6 & 4.6 \\
\hline Total & 129 & 100 \\
\hline Per capita income (INR) & & \\
\hline$\leq 3000$ & 76 & 58.9 \\
\hline $3000-6000$ & 27 & 20.9 \\
\hline $6000-9000$ & 10 & 7.7 \\
\hline$>9000$ & 16 & 12.5 \\
\hline Total & 129 & 100 \\
\hline
\end{tabular}

Table 4.Work place hazard exposure among study subjects*

\begin{tabular}{|c|c|c|}
\hline Work place hazard & Frequency & Percentage \\
\hline Thermal Stress & 70 & 54.3 \\
\hline Dust & 69 & 53.5 \\
\hline Noise & 49 & 38 \\
\hline Smoke & 39 & 30.2 \\
\hline Cold & 14 & 10.9 \\
\hline Welding & 12 & 9.3 \\
\hline Hand-arm Vibration & 11 & 8.5 \\
\hline Gases & 10 & 7.8 \\
\hline Fumes & 9 & 7 \\
\hline General Vibration & 9 & 7 \\
\hline Powders & 6 & 4.7 \\
\hline Aerosol & 4 & 3.1 \\
\hline Chemicals & 3 & 2.3 \\
\hline Raised Pressure & 1 & 0.8 \\
\hline
\end{tabular}

*Multiple response table.

Table 4, shows various work place hazards identified among the construction workers. Thermal stress affected the maximum number of workers (54.3\%), followed by dust (53.5\%), followed by noise (38\%). No worker was exposed to acids, alkalis or solvents.

On enquiring about the injuries suffered by the construction workers; 23\% (30) workers had frequent injuries, 15.5\% (20) workers had injuries by falling objects, $11.6 \%$ (15) had sprains and $10.1 \%$ (13) workers had falls. 
Table 5. Association of age and working hours with various injuries.

\begin{tabular}{|c|c|c|c|c|c|c|c|c|c|c|c|c|}
\hline $\begin{array}{l}\text { Age } \\
\text { (in } \\
\text { vears) }\end{array}$ & Frequen & injuries & $\begin{array}{c}\mathrm{P}- \\
\text { value }\end{array}$ & & Ils & $\begin{array}{c}\mathrm{p}- \\
\text { value }\end{array}$ & $\begin{array}{r}\text { Injury b } \\
\text { obj }\end{array}$ & $\begin{array}{l}\text { falling } \\
\text { ct }\end{array}$ & $\begin{array}{c}p- \\
\text { value }\end{array}$ & Spr & & $\begin{array}{c}\text { p- } \\
\text { value }\end{array}$ \\
\hline & Present & Absent & \multirow{3}{*}{0.230} & Present & Absent & \multirow{3}{*}{0.543} & Present & Absent & \multirow{3}{*}{0.429} & Present & Absent & \multirow{3}{*}{0.561} \\
\hline$<35$ & $24(26.1)$ & 68 (73.9) & & $9(9.8)$ & $83(90.2)$ & & $16(17.4)$ & $\begin{array}{c}76 \\
(82.6)\end{array}$ & & $11(12)$ & $81(88)$ & \\
\hline$>35$ & $6(16.2)$ & $31(83.8)$ & & $4(10.8)$ & $33(89.2)$ & & $4(10.8)$ & $\begin{array}{c}33 \\
(89.2) \\
\end{array}$ & & $4(10.8)$ & $\begin{array}{c}33 \\
(89.2) \\
\end{array}$ & \\
\hline \multicolumn{13}{|c|}{ Hours of work } \\
\hline$\leq 8$ & 4 (10.5) & 34 (89.5) & \multirow{4}{*}{0.002} & $4(10.5)$ & $34(89.5)$ & \multirow{4}{*}{0.587} & $4(10.5)$ & $\begin{array}{c}34 \\
(89.5)\end{array}$ & \multirow{4}{*}{0.05} & $3(7.9)$ & $\begin{array}{c}35 \\
(92.1)\end{array}$ & \multirow{4}{*}{0.392} \\
\hline $8-12$ & $20(24.4)$ & $62(75.6)$ & & $8(9.8)$ & $74(90.2)$ & & $12(14.6)$ & $\begin{array}{c}70 \\
(85.4) \\
\end{array}$ & & $\begin{array}{c}10 \\
(12.2) \\
\end{array}$ & $\begin{array}{c}72 \\
(87.8) \\
\end{array}$ & \\
\hline$>12$ & $6(66.7)$ & $3(33.3)$ & & 1 (11.1) & $8(88.9)$ & & $4(44.4)$ & $5(55.6)$ & & $2(22.2)$ & $7(77.8)$ & \\
\hline Total & 30 & 99 & & 13 & 116 & & 20 & 109 & & 15 & 114 & \\
\hline
\end{tabular}

There was no significant association between age and injuries among the study subjects when divided by age as less than and more than 35 years.

However, number of working hours were significantly associated with frequent injuries $(p<0.01)$. Falling of objects was also significantly associated with number of working hours $(p=0.05)$.

\section{Health Assessment}

On assessing the overall health, around $10 \%$ (13) of the workers complained of having some health problem. Various complaints were generalised body ache, headache, weakness, fever, cough, cold, blood in sputum, decreased appetite and blood in stools. About $5 \%$ of the workers were currently on some medication.

Around $17 \%$ workers reported to be smoking currently, $2 \%$ workers smoked previously and about $81 \%$ workers reported to have never smoked. Out of those who were currently smoking, majority were using bidi, followed by cigarette and hukkah. The number smoked ranged from 1 to 4 times per day.

Out of the total 129 workers, around $80 \%$ reported not using alcohol at all, $17 \%$ used alcohol occasionally and $3 \%$ frequently.

Random blood sugar was measured for all the participants, almost all the workers had random blood sugar less than $140 \mathrm{mg} / \mathrm{dl}$. Only 2 participants had random blood sugar $>140 \mathrm{mg} / \mathrm{dl}$.

On recording the blood pressure for all the study participants, almost all the workers had systolic blood pressure $<140$ $\mathrm{mm} \mathrm{Hg}$ and diastolic blood pressure $<90 \mathrm{~mm} \mathrm{Hg}$. Only 2 workers had systolic blood pressure $>140 \mathrm{~mm} \mathrm{Hg}$.

\section{Discussion}

In the current study, the mean age of the construction workers was 31.4 years, this is comparable with studies conducted in Kerala, ${ }^{5}$ Mumbai $^{6}$ and Kolkata ${ }^{7}$ where the mean age of the construction workers was 26.8, 26.85 and 32 years respectively.

In the present study, maximum workers originally belonged to Bihar and Uttar Pradesh, this is consistent with the study conducted by Payal $S$ et al. ${ }^{6}$ where majority of workers had migrated from West Bengal, Bihar and Uttar Pradesh as well as a study conducted by Guddu Tiwary et al. ${ }^{7}$ which found that majority of the workers were migrant.

Around $65 \%$ of the workers were married in the current study, which is similar to the findings reported in studies conducted in Mumbai ${ }^{6}$ where $58.9 \%$ workers were married and Kolkata ${ }^{7}$ where $61 \%$ workers were married. This is in contrast to the findings of a study conducted by Daljeet kaur et al. ${ }^{8}$ loss of employment, disability and loss of productivity and subsequently to families and Society. However, there is paucity of studies to elucidate the state of affairs in most of the part of India. The Present study dictates the prevalence of injury and associated factors among Bridge Construction workers in urban area of Mumbai. Objectives are (1 in Mumbai, where only 32\% workers were married. The difference can be attributed to the fact that this study included workers who were working at a specific bridge construction site for at least 3 months, which is more likely to involve workers who are not rapidly traveling and migrating which might constitute more of single, widowed or divorced people.

The education status of the construction workers was found to be low in this study, around 35\% workers were 
illiterate. This is consistent with studies done by Payal S et al. ${ }^{6}$ where $32.8 \%$ workers and Balkrishna et al. ${ }^{9}$ where 33.4\% workers were illiterate. Mesafint Molla et al. ${ }^{10} 2009$ at six licensed construction sites in Gondar city. A total of 401 building construction workers were included in the study by using simple random sampling technique. Data were collected through interviews using structured and pre-tested questionnaire and the collected data were entered and analyzed using Statistical Package for the Social Sciences (SPSS reported in a study conducted in Ethiopia that $17.2 \%$ workers were illiterate (cannot read and write). This variation could be due to difference between the two countries, the level of development, and socioeconomic difference.

In the present study, majority of the workers worked for 8 to 12 hours. Similar results were found in a study by Guddu Tiwary et al. ${ }^{7}$ that construction workers had to work for 10-12 hours per day. Workers usually work for longer time to earn more wages and to meet the basic needs of life. Although the result is in contrast to the observation made by Daljeet Kaur et al. ${ }^{8}$ loss of employment, disability and loss of productivity and subsequently to families and Society. However, there is paucity of studies to elucidate the state of affairs in most of the part of India. The Present study dictates the prevalence of injury and associated factors among Bridge Construction workers in urban area of Mumbai. Objectives are (1 in Mumbai, where almost half of the workers worked for $<8$ hours, this can be due to stricter adherence to laws pertaining for labour welfare in that particular area where the study was conducted.

The average income of the workers in the current study was Rs.11,972. Guddi Tiwary et al. ${ }^{7}$ in their study found that the average monthly income of the construction workers was Rs. 4956 and that the workers were exploited by labour contractors. The reason for this discrepancy can be the difference in the study area, the present study is carried out in Delhi where income and expenditure are more than some states in the country as well as the fact that the study by Guddu Tiwary et al was conducted around 8 years before the present study. In this study, 2.3\% workers were below poverty line while Payal S et al[6] found that $8.3 \%$ of the participants were below poverty line.

The major hazards faced by the workers in the current study were thermal stress, dust and noise. In addition, $23 \%$ workers suffered from frequent injuries, $10 \%$ had falls and $15 \%$ had injury by falling object, nearly similar results were reported by Daljeet kaur et al. ${ }^{8}$ loss of employment, disability and loss of productivity and subsequently to families and Society. However, there is paucity of studies to elucidate the state of affairs in most of the part of India. The Present study dictates the prevalence of injury and associated factors among Bridge Construction workers in urban area of Mumbai. Objectives are (1 where 25\% workers suffered from injuries, $5 \%$ had falls and $25 \%$ had injury by falling object. Relatively lower prevalence (12\%) of injuries was found by Thayyil et al. ${ }^{5}$ in a study conducted in Kerala. The reason could be explained by the fact that Thayyil et al had considered injuries only in the past one year, while in our study frequent injuries without any time constraint was taken into consideration. Even lower prevalence $(7.9 \%)$ was seen among construction workers in Mumbai by Balkrishna et al. ${ }^{9}$ the reason for which can be more mechanized work done at that site and presence of regular training of workers. Construction industry workers frequently suffer injuries, most of which can be prevented.

In the present study, overall, $10 \%$ workers reported some or the other health problem. The various health problems reported were musculoskeletal, respiratory and gastric problems. Almost similar health issues were reported by Gurav et al. ${ }^{11}$

Nearly $17 \%$ workers in this study were smoking and using alcohol. The finding of the present study was relatively consistent with the study conducted by Payal S et al. ${ }^{6}$ where $21.6 \%$ workers were smoking tobacco and $15.6 \%$ workers were using alcohol. Balkrishna et al. ${ }^{9}$ reported that around $14 \%$ workers were consuming alcohol. This finding was markedly lower than that of the study conducted in West Bengal where the prevalence of smoking among workers was $53 \%$ and that of alcohol consumption was $37 \%$. This discrepancy may be linked to the fact that workers would be smoking and consuming alcohol to relieve stress and anxiety due to long working hours. In fact, it was found that in many cases alcohol was provided by the employer himself in lieu of extra work shifts.

The study revealed that only $1.5 \%$ workers had deranged random blood sugar and high systolic blood pressure. Further tests like fasting blood sugar and $\mathrm{HbA} 1 \mathrm{c}$ are required to confirm diabetes in such individuals, and blood pressure charting has to be done for confirming hypertension. Even lesser prevalence was found by Gurav et al. ${ }^{11}$ where only $0.69 \%$ workers had hypertension. Although, in a study conducted by Joanne wai et al. ${ }^{12}$ in Hong Kong reported $7.8 \%$ construction workers to be diabetic and $81.3 \%$ to have intermediate or poor blood pressure. This variation could be due to the fact there is a major difference in the lifestyle, health behaviours and the presence of a wide economic gap between the two countries.

\section{Limitations of the Study}

It is health camp-based study which may not cater true construction workers population; therefore, findings may not be generalizable. Those workers who were seriously ill may not have come to attend the health camp. 


\section{Conclusion}

The study depicted that a large proportion of construction workers were working for long hours with wide range of per capita income. There was a high prevalence of frequent injuries and falls. Workers were exposed to various workplace hazards including smoking and alcohol use. The findings of the study highlighted the importance of regulating work hours of the construction workers, periodic training on safe work culture and ways to reduce workplace injuries. Counter measures such as provision of occupational health services, awareness as well as reducing hazard exposure among construction workers may increase their general living conditions.

\section{Conflict of Interest: None}

\section{References}

1. International Labour Organization. Global Trends on Occupational Accidents and Diseases. World Day Saf Heal Work [Internet]. 2015; 1-7. Available from: http:// www.ilo.org/legacy/english/osh/en/story_content/ external_files/fs_st_1-ILO_5_en.pdf.

2. https://shodhganga.inflibnet.ac.in/bitstream/1 0603/164965/9/09_chapter\%206.pdf.

3. Biswas G, Bhattacharya A, Bhattacharya R. Occupational health status of construction workers: A review. Int J Med Sci Public Heal 2017; 6(4): 1.

4. Institute for Human Development. India Labour and Employment Report 2014. 2014; 4-5. Available from: http://www.ihdindia.org/ILERpdf/Highlights of the Report.pdf.

5. Jayakrishnan T, Thomas B, Rao B, George B. Occupational health problems of construction workers in India. Int J Med Public Heal 2013; 3(4): 225.

6. Laad PS, Adsul BB, Chaturvedi RM, Shaikh M. Prevalence of Substance Abuse among Construction Workers. Res Pap 2013; 280-283.

7. SES constr workers.

8. Kaur D, Rajan lilare R, Dilip Rathod N, Datta B, Kaswan P. An organization based cross-sectional study of occupational injuries among bridge construction workers in an urban area of Mumbai. Int J Community Med Public Heal 2019; 6(3): 1211.

9. Adsul BB, Laad PS, Howal PV, Chaturvedi RM. Health problems among migrant construction workers: $A$ unique public-private partnership project. Indian J Occup Environ Med 2011; 15(1): 29-32.

10. Adane MM, Gelaye KA, Beyera GK, Sharma HR. Occupational Injuries Among Building Construction Workers in Gondar City, Ethiopia. Occup Med Heal Aff 2013; 01(05): 1-5.

11. Gurav RB, Kartikeyan S, Wayal R, Joshi SD. Assessment of health profile of daily wage labourers. Indian J Occup Environ Med 2005; 9(3): 115-117.
12. Chung JW, Wong BY, Yan VC, Chung LM, So HC, Chan A. Cardiovascular Health of Construction Workers in Hong Kong: A Cross-Sectional Study. (Ci):1-20. 